\title{
Употребление показателей множественного числа существительных в современных халха-монгольском и бурятском языках
}

\section{Анна Владимировна Мазарчук ${ }^{1}$}

\author{
${ }^{1}$ Институт лингвистических исследований РАН (д. 9, Тучков переулок, 199053 Санкт- \\ Петербург, Российская Федерация) \\ младший научный сотрудник \\ iD 0000-0003-3679-2858. E-mail: anja_av@rambler.ru
}

(C) КалмНЦ РАН, 2020

(C) Мазарчук А. В., 2020

\begin{abstract}
Аннотация. Введение. В статье сравнивается употребление маркеров плюралиса существительных в современных халха-монгольском и бурятском языках. В монгольских языках использование показателей множественного числа существительных факультативно. При этом в бурятском языке они употребляются чаще, чем в монгольском. Цель. Чтобы выяснить, насколько сильно разнятся количественные показатели на сегодняшний день (и уже на основании этих данных делать какие-то выводы), автор собрал два мини-корпуса газетных статей схожей тематики (политика, экономика, культура, спорт), опубликованных в интернет-версии монгольской газеты «Өнөөдөр» и бурятской интернет-газете «Буряад үнэн» с апреля по август 2020 г. — в период, непосредственно предшествовавший началу данного исследования: автору было важно, чтобы данные максимально отражали сегодняшнее состояние языка. Объем мини-корпуса монгольских текстов составляет 10032 словоупотребления, бурятского - 10261 словоупотребление. Материалом исследования стали именно газетные тексты, так как они быстрее и в большем объеме, чем художественные или научные, вбирают в себя новшества, появляющиеся в языке. Наиболее достоверные результаты мог бы дать анализ полевого материала, но сейчас проведение полевых исследований затруднено из-за эпидемической ситуации. Было решено собрать материалы вручную, а не пользоваться имеющимися в общем доступе «большими» корпусами, поскольку требовалось сравнить тексты, аналогичные по тематике, объему и времени создания, а в «больших» корпусах не всегда технически возможно ограничить сферу поиска, что затрудняет сравнение количественных данных по двум языкам. Результаты. Собранный материал показывает, что в монгольских публицистических текстах маркеры плюралиса существительного употребляются в среднем в 3,5 раза реже, чем в бурятских. В то же время известно, что в памятниках среднемонгольского языка маркеры множественного числа встречаются в 4 раза чаще, чем в современном халха-монгольском языке. В заключении автор формулирует вопросы, возникшие после получения количественных данных и требующие дальнейшего изучения.
\end{abstract}


Ключевые слова: монгольские языки, современный монгольский язык, среднемонгольский язык, халха-монгольский язык, бурятский язык, калмыцкий язык, множественное число, морфология, языковые контакты

Благодарность. Исследование выполнено при финансовой поддержке РФФИ и МинОКН Монголии в рамках научного проекта № 19-512-44006 «Взаимодействие языков в поликультурном пространстве на материале монгольских языков: сравнительный анализ калмыцкого языка, языка ойратов Монголии и бурятского языка». Материалы статьи апробированы на Международной научной онлайн-конференции «Монголоведение в начале XXI в.: современное состояние и перспективы развития II», проведенной при финансовой поддержке РФФИ (проект № 20-09-22004) и частичной поддержке гранта Правительства РФ (№ 075-15-2019-1879).

Для цитирования: Мазарчук А. В. Употребление показателей множественного числа в современных халха-монгольском и бурятском языках // Монголоведение. 2020. Т. 12. № 4. C. 660-667. DOI: 10.22162/2500-1523-2020-4-660-667

UDC $81-26$

DOI: $10.22162 / 2500-1523-2020-4-660-667$

\title{
The Use of Nominal Plurality Markers in Modern Khalkha Mongolian and Buryat
}

\author{
Anna V. Mazarchuk ${ }^{1}$ \\ ${ }^{1}$ Institute for Linguistic Studies of the RAS (9, Tuchkov Lane, St. Petersburg 199053, \\ Russian Federation) \\ Junior Research Associate
}

iD 0000-0003-3679-2858. E-mail: anja_av@rambler.ru

(C) KalmSC RAS, 2020

(C) Mazarchuk A. V., 2020

\begin{abstract}
Introduction. The article deals with the use of nominal plurality markers in modern Khalkha and Buryat. Nominal plurality markers are used optionally in the Mongolic languages. However, in Buryat they are used more often than in Khalkha. Goals. In order to find out how much the figures differ at the moment (and then make some relevant conclusions), the author has collected two small corpora of newspaper articles on politics, economy, culture, and sports published in the Buryat online newspaper Buryad Unen and Mongolian webbased edition Unuиdur written from April to August of 2020 - in the period preceding the start of this research, as it was critical for the author to have the utmost up-to-date materials. Materials. The Mongolian mini-corpus comprises 10032 words, and the Buryat mini-corpus consists of 10261 words. Newspaper articles have been chosen as study material because publicistic writings absorb language novelties faster and in greater amount than fiction or scholarly works, thus better reflecting the present-day state of the language. The field data could be a more reliable source of material but field work is currently hindered because of the epidemic situation. The author decided not to use the online corpora, which are way bigger than the manually collected ones (and this is certainly their great advantage) because it was necessary to compare texts similar in subject and volume, and written approximately at the same period of time. It is not always technically feasible to restrict the field of search in the online corpora, which makes it difficult to compare the obtained results for the two
\end{abstract}




\section{Монголоведение • Mongolian Studies • 2020 ๑ T. 12 • № 4}

languages. Results. The collected data shows that in the Mongolian newspaper articles the plurality markers are used about 3,5 times as frequently as in the Buryat ones. Along with it, Middle Mongolian plurality markers are known to have been used about four times as frequently as in Modern Mongolian. In the conclusion the author poses questions for further study which arose after obtaining the quantitative data.

Keywords: Mongolic languages, Modern Mongolian, Middle Mongolian, Khalkha, Buryat, Kalmyk, plurality, morphology, language contacts

Acknowledgements. The reported study was funded by RFBR and Ministry of Education, Culture, Sciences and Sports of Mongolia, project no. 19-512-44006 'Language Contact in Multicultural Contexts: Comparative Analysis of Mongolic Languages (Case Studies of Kalmyk, Oirat in Mongolia and Buryat)' (state re. no. AAAA-A19-119080790033-3).

The article was presented at the International scientific online conference 'Mongolian Studies at the Beginning of the $21^{\text {st }}$ Century: Current State and Development Prospects - II' funded by RFBR (project no. 20-09-22004) and Government of Russia (grant no. 075-15-20191879).

For citation: Mazarchuk A. V. The Use of Nominal Plurality Markers in Modern Khalkha Mongolian and Buryat. Mongolian Studies (Elista). 2020. Vol. 12. No. 4. Pp. 660-667. (In Russ.). DOI: 10.22162/2500-1523-2020-4-660-667

Как известно, в монгольских языках множественное число существительных маркируется факультативно. Вместе с тем частота употребления показателей плюралиса в разных монгольских языках отличается. Интересно, что и в диахронии она не является константой: так, в памятниках среднемонгольского языка маркеры множественного числа употребляются в четыре раза чаще, чем в современном халха-монгольском языке [Street 1990: 374] (цит. по: [Oxford Guide 2020: 522]). Чтобы получить какие-то синхронные количественные данные, на которые можно было бы опираться при изучении данной темы, было собрано два мини-корпуса газетных текстов, написанных в последние месяцы: один корпус на монгольском, другой - на бурятском языке (объем каждого корпуса составил около 10000 словоупотреблений).

Монгольский и бурятский языки родственны генетически и близки географически, но отличаются по своему статусу, количеству носителей и пройденному историческому пути. Монгольский - официальный язык независимого государства Монголии; бурятский - находящийся под угрозой исчезновения язык республики, входящей в состав Российской Федерации. Население Монголии - 3,2 млн чел., 94 \% из них - этнические монголы, носители собственно монгольского языка. Носителей бурятского языка в России около 300 тыс. чел., и их языковое окружение формируют в основном люди, для которых первым (родным) языком стал русский. Возможно, на частоту употребления показателей множественного числа существительных оказали и эти факты. Как бы то ни было, необходимо иметь точное (в том числе и с точки зрения цифр) представление об исследуемом предмете. Именно для этой цели и были собраны мини-корпусы.

Более глубокое исследование вопроса предполагает сбор полевого материала и исследование устной речи, но в нынешних условиях проводить масштабные полевые исследования довольно трудно, поэтому на данном этапе было решено ограничиться изучением письменных источников. Выбор жанра 
исследуемых текстов обусловлен тем, что публицистика быстрее, чем художественные или научные тексты, реагирует на изменения, происходящие в языке, вбирая в себя большее количество вновь появляющихся в языке элементов, и, таким образом, в большей степени, чем тексты других жанров, отражает современное состояние языка.

Исследование проводилось не на имеющихся в общем доступе корпусах, а на текстах, собранных вручную, в силу следующих обстоятельств: во-первых, в монгольском корпусе, к сожалению, не работает настройка подкорпусов и поиск словоформ по заданным грамматическим параметрам; во-вторых, бурятский и монгольский корпусы — разные по объёму (1 млн 200 тыс. и 2 млн 200 тыс. словоупотреблений соответственно), а это делает затруднительным сравнение количественных данных, автоматически выдаваемых корпусами при поиске словоформ. Поэтому, чтобы сравниваемый материал был аналогичным по объёму и жанру, было необходимо собрать корпусы текстов вручную.

Корпус исследуемых бурятских текстов (10 261 словоупотребление) составили статьи различной тематики из интернет-газеты «Буряад үнэн» ${ }^{1}$, вышедшие в апреле-июне 2020 г. Корпус монгольских текстов (10 032 словоупотребления) - новости политики и культуры, опубликованные в августе 2020 г. в интернет-версии газеты «Өнөөдөр»².

В монгольском и бурятском языках используются аналогичные показатели множественного числа (табл. 1). Единственное формальное различие между наборами монгольских и бурятских маркеров плюралиса — отсутствие в бурятском и наличие в монгольском показателя -c. Этот показатель существовал еще в протомонгольском языке [ML 2003: 12], и в монгольском этот маркер плюралиса прижился, а в бурятском - нет [ГБЯ 1962: 72-75; Цыдендамбаев 1979: 25-36]. В современном халха-монгольском языке аффикс множественного числа - с считается редким; в грамматике Д. Цэрэнпила и Р. Кульман ука-

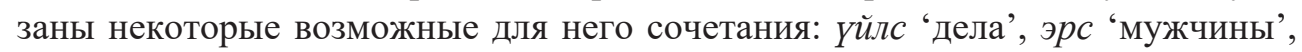
нэрс 'имена', залуус 'молодые [люди]', үрс 'потомки', дээдэс '[представители] высшего сословия; предки', доодос '[представители] низшего сословия', юмс 'вещи', үгс ‘слова', уулс ‘горы' [Tserenpil 2008: 75]. В нашем монгольском мини-корпусе было найдено всего два слова, форма плюралиса которых была образована с помощью данного форманта: зүйлсэд 'в вещах' (зүйл-с-эд <вещьPL-DAT>) и изэцэгсийн 'цветов' (цэиээг-с-ийн <цветок-PL-GEN>). Аффикс -c также участвует в образовании формы множественного числа слова монг. $x_{Y}$ 'человек' - хүмүYс 'люди', но в синхронии это не очевидно. ХүмүYс - это дошедшая до наших дней и используемая в современном языке форма плюралиса от слова письм. монг. küтӥn, которое в свою очередь трансформировалось в $x Y н$. Можно сказать, что форма $\chi_{Y м} Y_{Y}$ лексикализовалась. Поэтому она не была внесена в общий список плюральных словоформ, и 10 употреблений словоформы $х Y_{Y} Y{ }^{\prime}$, встретившиеся в монгольском мини-корпусе, посчитаны не были.

\footnotetext{
${ }^{1}$ Интернет-газета «Буряад үнэн» [электронный ресурc] // URL: https://burunen.ru/ (дата обращения: 15.09.2020).

${ }^{2}$ Интернет-газета «Өнөөдөр» [электронный ресурс] // URL: https://unuudur.mn/ (дата обращения: 18.09.2020).
} 


\section{Монголоведение • Mongolian Studies • 2020 ๑ T. 12 • № 4}

Монгольские маркеры плюралиса $-y y \partial^{2}$ и -нуy $\partial^{2}$ помещены в одну графу и посчитаны вместе, так как по сути являются алломорфами одной морфемы: -н-, либо когда основа заканчивается на долгий гласный или дифтонг. Суффикс -чууд $\partial^{2}$ несет в себе семантику собирательности, поэтому он был посчитан

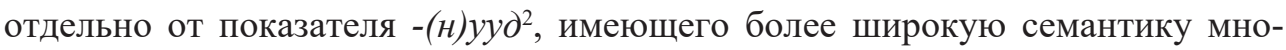
жественности. У Д. Цэрэнпила и Р. Кульман [Tserenpil 2008: 74] сказано, что суффикс -чууд $\partial^{2}$ имеет реже употребляемый вариант -чуул ${ }^{2}$. В нашей монгольской выборке не встретилось ни одного сочетания с -чуул ${ }^{2}$. В бурятском же мини-корпусе, напротив, встретились примеры сочетаний с -шуул ${ }^{2}$ (6 раз), но ни разу не попались примеры с -шууд ${ }^{2}$, хотя этот суффикс указан в грамматиках и справочниках среди остальных маркеров плюралиса существительных (например, [ГБЯ 1962: 74]). Знание того, что монг. -чууд ${ }^{2}$ имеет вариант -чуул ${ }^{2}$, а бур. -шуул ${ }^{2}$ имеет вариант -шууд ${ }^{2}$, позволило нам поместить монг. -чууд² и бур. -шуул ${ }^{2}$ в одну строчку как соответствующие друг другу форманты (которые можно сравнивать). Стоит также сказать, что в таблице отдельно не отмечены встречающиеся в монгольском и бурятском языках и отмеченные в грамматиках данных языков алломорфы -гууд ${ }^{2}$, поскольку нам они представляются вариантами маркера -(н)ууд2: согласный -г- появляется в данном суффиксе после основ со скрытым -2.

Итак, каковы же полученные количественные данные? В монгольском мини-корпусе объемом 10032 словоупотребления всего встретилось 157 случаев употребления формантов множественного числа существительного. Получается, что в среднем в рассматриваемых монгольских текстах плюралис маркируется в каждом 64-м слове. В то время как в бурятском корпусе (10 261 словоупотребление) было обнаружено 559 случаев употребления маркеров множественного числа, что примерно в 3,5 раза больше, чем в монгольском мини-корпусе. В бурятском корпусе, таким образом, один маркер плюралиса в среднем приходится на каждое 18-е слово.

Усредненные показатели удобны для того, чтобы оценивать общие тенденции, но иногда могут создавать ложное представление о наблюдаемой картине. Поэтому следует уточнить, что для собранных корпусов более характерно неравномерное распределение маркеров плюралиса в тексте: даже в бурятском корпусе встречаются довольно длинные отрывки текста (до 178 слов), где ни один из рассматриваемых показателей ни разу не используется. Но также часто можно видеть формы множественного числа, идущие друг за другом или через одно-два слова (1):

(1) Ороходо аманай хаалтанууд, перчатканууд, ручканууд үгтэнэ, арюудхаха ажалнууд хэгдэнэ 'При входе выдаются маски, перчатки и ручки; проводятся работы по дезинфекции'.

В монгольском мини-корпусе встретилось только одно предложение, где две формы плюралиса оказались расположены друг за другом (2):

(2) Тус лобби бүлэгт Ж. Чинбүрэн, С. Амарсайхан, П. Анужин, Ё. Баатарбилэг, Э. Бат-Амгалан, Б. Бейсен, С. Ганбаатар, Х. Ганхуяг, Ж. Мөнхбат, Ц. Мөнх-Оргил, С. Одонтуяа, М. Оюунчимэг, Б. Саранчимэг, Ц. Туваан, Н. Учрал, Ц. Цэрэнпунцаг, Л. Энх-Амгалан, Т. Энхтүвщин нарын гишүүд нэгдсэн юм. 'В данной лоббирующей группе объединились члены [ВГХ] Ж. Чинбурэн, 
С. Амарсайхан, П. Анужин, Ё. Баатарбилэг, Э. Бат-Амгалан, Б. Бейсен, С. Ганбаатар, Х. Ганхуяг, Ж. Мунхбат, Ц. Мунх-Оргил, С. Одонтуяа, М. Оюунчимэг, Б. Саранчимэг, Ц. Туваан, Н. Учрал, Ц. Цэрэнпунцаг, Л. Энх-Амгалан, Т. Энхтүвшин'.

В большинстве случаев в рассматриваемых монгольских текстах, если в предложении есть форма множественного числа, то она одна. Реже встречаются предложения, где есть две формы плюралиса. Предложений, в которые входило бы три существительных в форме множественного числа, в монгольском мини-корпусе обнаружено не было.

В рассматриваемых монгольских и бурятских текстах самыми частотными оказался показатель -(н)yуд ${ }^{2}$, что было довольно ожидаемо: в грамматиках -(н) $y y \partial^{2}$ называют самым распространенным маркером плюралиса [Tserenpil 2008: 72; ГБЯ 1962: 72]. В монгольском мини-корпусе этот формант встречается 77 раз, в бурятском - 354 раза (в 4,6 раз чаще, чем в монгольском). Вторым по частоте употребления оказался формант - 2 : в монгольском - 62 формы, в бурятском - 170 (в 2,7 раз больше). Показатель нар в монгольских текстах и -нар ${ }^{3}$ в бурятских встречаются значительно реже, чем описанные выше форманты: в монгольском мини-корпусе выявлено 13 случаев употребления, в бурятском - 35 (что в 2,7 раз больше, чем в монгольском). Монгольских форм с -чууд ${ }^{2}$ в исследуемых текстах в 3 раза меньше, чем бурятских с -шуул ${ }^{2}$ (2 и 6 соответственно). О монгольских формах плюралиса на -с было сказано выше.

Таблица 1. Монгольские и бурятские показатели плюралиса

[Table 1. Mongolian and Buryat plurality markers]

\begin{tabular}{|c|c|c|c|}
\hline \multicolumn{2}{|c|}{ Монгольский мини-корпус } & \multicolumn{2}{|c|}{ Бурятский мини-корпус } \\
\hline$-(H) y y \partial^{2}$ & 77 & $-(H) y y \partial^{2}$ & 354 \\
\hline$-ч y y \partial^{2}$ & 2 & $-ш у у л^{2}$ & 6 \\
\hline нар & 13 & $-H a p^{3}$ & 35 \\
\hline$-\partial$ & 62 & $-\partial$ & 170 \\
\hline$-c$ & 2 & - & - \\
\hline
\end{tabular}

Что касается лексики, оформляемой данными показателями, то можно увидеть некоторые пересечения множеств (табл. 2): суффиксом -(н)ууд² оформлено 2 слова монг. ажлууд и 9 слов бур. ажалнууд 'работы', 1 слово монг. аймгууд и 13 бур. аймагууд 'аймаки', 1 слово монг. газрууд и 8 бур. газарнууд, 1 слово монг. нутгууд и 5 бур. нютагууд 'родные места', 1 слово монг. орнууд и 2 бур. оронууд ‘страны', по 1 слову монг. хотууд и бур. хотонууд 'города'. Аффиксом нар / -нар по одному разу в бурятских и монгольских текстах оформлено слово дарга 'начальник': монг. дарга нар и бур. дарганар. С помощью суффикса оформлены следующие слова: монг. гищүУд (27 словоупотреблений), бур. гэщүҮд (6 словоупотреблений) 'члены (организации)'; монг. нөхөд (1), бур. нүхэд (7) ‘товарищи’; монг. оролцогчид (2), бур. оролсогшод (2) 'участники'; монг. тамирчид (5), бур. тамириад (3) ‘спортсмены’; монг. эрхлэгчид (6), бур. эрхилэгшэд (3) ‘управляющие'. 
Таблица 2. Лексемы, оформленные аналогичными маркерами плюралиса [Table 2. Lexemes shaped by similar plurality markers]

\begin{tabular}{|c|c|c|c|}
\hline \multicolumn{2}{|c|}{ Монгольский мини-корпус } & \multicolumn{2}{|c|}{ Бурятский мини-корпус } \\
\hline \multicolumn{4}{|c|}{$-(\boldsymbol{u}) y y d^{2}$} \\
\hline ажлууд & 2 & ажалнууд & 9 \\
\hline аймгууд & 1 & аймагууд & 13 \\
\hline газрууд & 1 & газарнууд & 8 \\
\hline нутгуууд & 1 & нютагууд & 5 \\
\hline орнууд & 1 & оронууд & 2 \\
\hline xотуyд & 1 & хотонууд & 1 \\
\hline \multicolumn{4}{|c|}{ Hap /-Hap } \\
\hline дарга нар & 1 & дарганар & 1 \\
\hline \multicolumn{4}{|c|}{$-\partial$} \\
\hline гишүҮд & 27 & гэщүYд & 6 \\
\hline нөхөд & 1 & нүхээд & 7 \\
\hline оролиогчид & 2 & оролсогшод & 2 \\
\hline тамирчид & 5 & тамирмад & 3 \\
\hline эрхлэгчид & 6 & эрхилэгшэд & 3 \\
\hline
\end{tabular}

Как видно в табл. 2, в большинстве случаев количество употреблений определенных форм плюралиса в бурятских текстах предсказуемо выше. Однако есть и исключения - монг. гишүҮд, тамирчид, эрхлэгчид. Возможно, их наличие свидетельствует о том, что маркирование плюралиса определенных слов в монгольском языке становится скорее обязательным, чем факультативным.

Если обобщить сказанное, то маркирование плюралиса в монгольских языках представляется отнюдь не линейным процессом: формантов плюралиса в бурятском языке чуть меньше, чем в монгольском, но они употребляются намного чаще; в монгольском множественное число маркируется в 3,5 раза реже, но некоторые существительные требуют обязательного маркирования множественного числа. Множественное число в бурятском языке маркируется почти так же часто, как оно маркировалось в среднемонгольских памятниках — получается, что обозначение множественного числа является архаичной чертой? Она сохраняется в бурятском языке сама по себе или благодаря внешнему воздействию со стороны русского языка? В норме, без активного влияния русского языка, с маркированием плюралиса в бурятском должно было произойти то же самое, что в монгольском, или монгольский вариант развития категории множественности - это не норма, а частный случай, обусловленный географией проживания и, как следствие, экстралингвистической реальностью, окружающей носителей языка? Могли ли на факультативность маркирования плюралиса в монгольском повлиять языковые контакты с «южным соседом»? Чтобы ответить на эти вопросы, нужно провести сравнительный анализ множества текстов, составленных на разных монгольских идиомах в разные периоды, - устных и письменных, переводных и оригинальных. Возможно, тогда найдутся ответы на эти вопросы.

\section{Сокращения}

DAT — датив; GEN — генитив; PL — плюралис; бур. — бурятский язык; монг. — монгольский язык. 


\section{Литература}

ГБЯ 1962 - Грамматика бурятского языка: Фонетика и морфология. М.: Вост. лит., $1962.340 \mathrm{c.}$

Цыдендамбаев 1979 - Цыдендамбаев Ц. Б. Грамматические категории бурятского языка в историко-сравнительном освещении. М.: Наука, 1979. 148 с.

ML 2003 - The Mongolic Languages / ed. by Juha Janhunen. London and New York: Routledge, 2003. 433 p.

Oxford Guide 2020 - The Oxford Guide to the Traseurasian Languages / ed. by Martine Robbeets and Alexander Savelyev. Oxford: Oxford University Press, 2020. 893 p.

Street 1990 - Street J. Nominal Plural Formations in the Secret History // Acta Orientalia Academiae Scientiarum Hungaricae. Tomus XLIV (3). 1990. Pp. 345-379.

Tserenpil 2008 — Kullmann R., Tserenpil D. Mongolian Grammar. Ulaanbaatar: Admon, 2008.448 p.

\section{References}

Janhunen J. (ed.) The Mongolic Languages. London, New York: Routledge, 2003. 433 p. (In Eng.)

Kullmann R., Tserenpil D. Mongolian Grammar. Ulaanbaatar: Admon, 2008. 448 p. (In Eng.)

Robbeets M., Savelyev A. (eds.) The Oxford Guide to the Transeurasian Languages. Oxford: Oxford University Press, 2020. 893 p. (In Eng.)

Sanzheev G. D. Buryat Grammar: Phonetics and Morphology. Moscow: Vostochnaya Literatura, 1962. 340 p. (In Russ.)

Street J. Nominal plural formations in the Secret History. Acta Orientalia Academiae Scientiarum Hungaricae. 1990. Vol. XLIV. No. 3. Pp. 345-379. (In Eng.)

Tsydendambaev Ts. B. Buryat Grammatical Categories: A Comparative Historical Perspective. Moscow: Nauka, 1979. 148 p. (In Russ.) 